\title{
El flúor en la prevención de caries en la denticion temporal. Barnices fluorados
}

The fluorine in the prevention of decay in the temporary teething. Fluorated varnishes

\section{Resumen}

Desde mediados del siglo $X X$, los trabajos de Cox, Dean $y$ Armstrong permitieron concluir que el Fluor aumenta la resistencia a la Caries Dental generando fluorosis en altas concentraciones (mayores de $1 \mathrm{ppm}$.

Hoy ,iniciando el siglo XXI y a pesar de todas las líneas de investigación sobre métodos preventivos de la Caries, ninguna propuesta ha superado al flúor como medida en costo, inocua y eficiencia. ${ }^{2}$

A continuación presentamos una revisión bibliográfica del Flúor como método preventivo de Caries Temprana, enfocándonos en el Barniz de Flúor y mostrando a la comunidad odontopediátrica el protocolo de aplicación.

\section{Abstract}

Since 1950, the investigations of Cox, Dean and A.rmstrong lead to conclude that fluoride increased the resistance to dental caries but produced fluorosis in high concentrations (over $1 \mathrm{ppm}$ )

Nowadays, in spite of the varied lines of research based in caries prevention methods, none of them has overcome Fluoride as a cheap, inotfensive and efficient method for this purpose. ${ }^{2}$

A review about Fluoride as an Early Childhood Dental Caries preventive method is presented, focused in fluoride varnishes. We also show the scheme of Fluoride application.

\section{Mecanismos de Acción}

El efecto preventivo de los fluoruros parece ser la suma de los resultados de diversos mecanismos:

$1^{\circ}$ Inhibición de la desmineralización y catálisis de la remineralización del esmalte desmineralizado.-

En los años 60, se creía que un efecto preventivo de caries dental se lograba por el incremento en la cantidad de flúor en la superficie del esmalte, lo que reducia su solubilidad, principalmente a través de la formación de fluorapatita ${ }^{2}$.

Sin embargo este concepto ha cambiado, a tribuyéndole el efecto preventivo a la presencia continua del ión flưor en el medio peridentario y no a la incorporación de flúor en el esmalte., Varios estudios demostraron que niveles altos de fúor en el esmalte no garantizan protección contra la caries

\section{dental. Arends, $1990 .^{5}$}

Diversas investigaciones concluyen que niveles adecuados de flúor on el fluido de la placa favorecen el equilibrio entre los ácidos orgánicos , fosfatos, calcio y otros que pudieran retardar o inhibir la producción ácida y/o promover la remineralización (Fejerskov, 1981, White et al 1994, Rolla, Ekstrand, 1996), 6,7

Por otro lado es importante resaltar el papel del fluoruro de calcio, molécula que precipita intrabucalmente y se mantiene por unas 25 semanas luego de una topicación (Ogaard, 1994)7. Otros han descrito una pérdida total de CaF2, después de 24 horas de una aplicación de fluoruro 8.9

El F2Ca cumple la función de reservorio de fluoruro ph dependiente, es estable en la saliva a un $\mathrm{pH}$ neutro y es el más importante surtidor de iones

\section{ARTíCULO DE REVISIÓN}

\section{Segundo Perales Zamora ${ }^{*}$; Celso \\ Guillen Borda ${ }^{2^{*}}$; Rosario Loayza De La Cruz;: Sergio Alvarado Menach $0^{4 *}$; Gilmer Torres Ramos ${ }^{5}$; Antonio Guillén Astete ${ }^{k}$ y Cynthia Anticona Huaynate ${ }^{7^{*}}$}

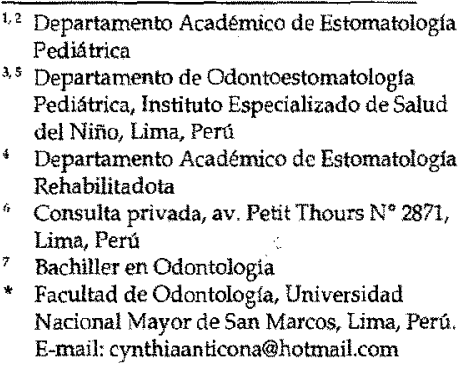

Palabras clave: Caries de infancia temprana, flúor, barniz fluorado.

Key words: Early childhood caries, fluoride, fluoride varnishes

fluoruro durante los cambios cariogenicos, cuando el descenso del ph baja mas de 5.0 (Rocin-Groget y Lincir 2001; ten cate, 1999$)^{7}$

De esta manera, el flúor se comportaría como un catalizador que permite una remineralización más rápida de las lesiones incipientes, requiriendo en promedio $100 \mathrm{ppm}(\mathrm{m} \mathrm{g} / \mathrm{L})$ de iôn flúor

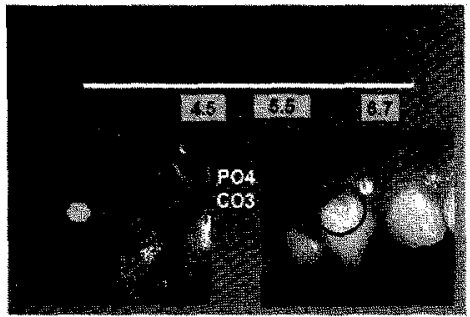

Fig.1: Proceso de desmineralización causado por un descenso del pH salival a niveles críticos. 
En condiciones normales el $\mathrm{pH}$ de saliva es 6.7 , cuando se consume carbohidratos fermentables y estos son metabolizados por las bacterias cariogénicas, provocan un descenso del $\mathrm{pH}$ a niveles críticos de 5,5 (fig. 1) para la HAP, existiendo algunos alimentos que producen un descenso aun mayor (4.5) crítico para FHAP traduciéndose estos procesos bioquímicas en pérdida de minerales (manchas blancas) y si esto continúa se observarán zonas cavitadas porque en todo momento lo único que se produce es perdida.

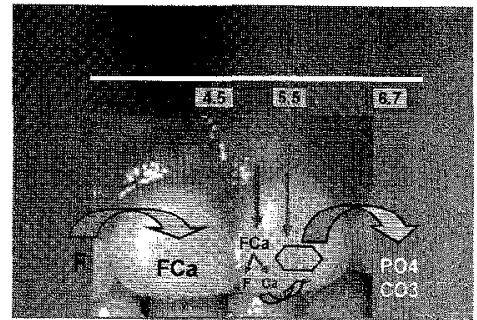

Fig. 2: Proceso de remincralización

Cuando el ácido presente en la interfase es neutralizado por sistemas tampón. (calcio, fosfatos) se produce una acumulación de $\mathrm{F}$ y $\mathrm{Ca}$ disponibles para volver a reaccionar y hacer posible la remineralización (fig. 2), formándose nuevas moléculas de HPA y FHPA (fig. 4). Además el esmalte desmineralizado tendría mayor capacidad de captar el flúor que el esmalte sano.

$2^{\circ}$ Transformación de la HAP en FAP, que es más resistente a la descalcificacion.-

Esta reacción química presenta una reversibilidad en función de la concentración de flúor en el entorno del esmalte dental, de modo que la FAP no sería una situación definitiva y estable. $^{1}$

Para poder realizar este mecanismose requiere $100 \mathrm{ppm}$ de ión flúor.

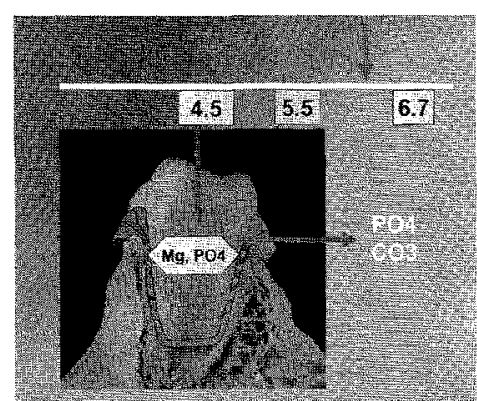

Fig.3: Proceso de desmineralización en una pieza dentaria en proceso de erupción

Cuando la piezas inician su erupción, la estructura del esmalte aun no completo su mineralización ya que la HAP tiene en su composición alto contenido de magnesio y fosfatos los que son mas solubles de manera tal que un descenso leve, $\sin$ llegar a 5.5 ya provoca desmineralización por lo tanto son mas susceptibles del ataque ácido (fig. 3).

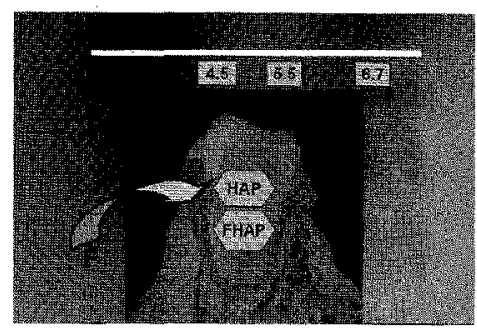

Fig. 4: Transformación de las moléculas de Hidroxiapatita en Fluorapatita

Cuandolas piezas en erupción reciben periódicamente aporte de flúor estas van a transformar HAP en FHAP (flúor hidroxiapatita) siendo esta última mas resistente a los ataques ácidos debiendo descender a un $\mathrm{pH} 4.5$.

$3^{\circ}$ Inhibición de las reacciones de glucólisis de las bacterias de la placa dental.- (sobre todo, Streptococcus mutans), con lo que disminuye la formación de ácidos (butírico y acético), indispensables para la descomposición de la HAP en iones calcio, fosfato y agua ${ }^{10}$.

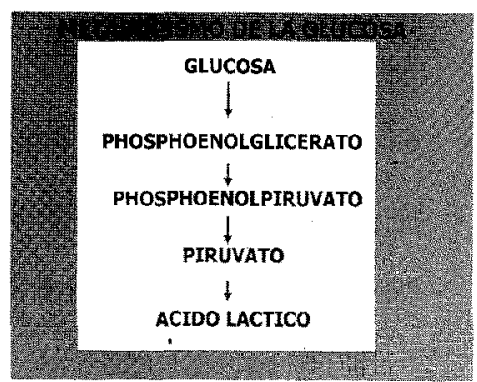

Fig. 5: Metabolismo de la glucosa y formación del ácido láctico

La glucosa al ser metabolizada por bacterias cariogénicas pasa un proceso bioquímico denominada la Vía de Emden Meyer Hoff Parnas, teniendo como producto final la producción de ácido láctico provocando un descenso del pHa 5.5 (fig. 5 ).

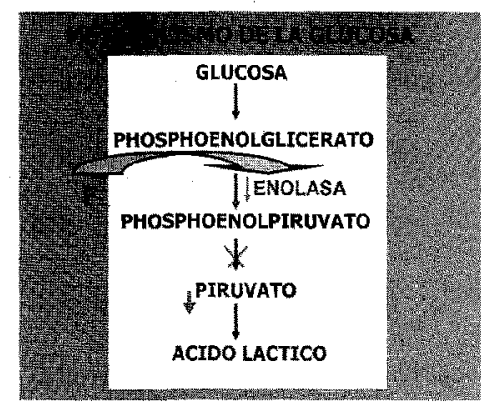

Fig. 6: El fluor interrumpe el proceso de formación del ácido láctico
Pero cuando hay un aporte de Flúor en promedio de 200 ppm esta inhibe la formación de ENOLASA encima importante en el circuito de la vía interrumpiendo el proceso normal y disminuyendo la producción final de ácido láctico (fig. 6).

$4^{\circ}$ Reducción de la producción de polisacáridos extracelulares en la placa dental.

La incorporación de fluor al esmalte reduce la fuerza electrostática que interviene en la adhesión de las bacterias y por tanto inhibe la formación de la placa bacteriana (fig. 8).

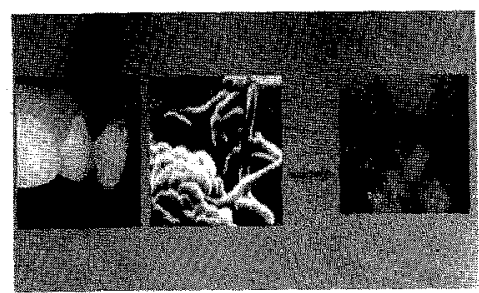

Fig. 7: Acúmuio de placa bacteriana en la superficie del esmalte

La carga electrostática de la superficie del esmalte es positiva y el de las bacterias negativas, por diferencia de cargas se atraen provocando gran acumulo de placa bacteriana (fig. 7).

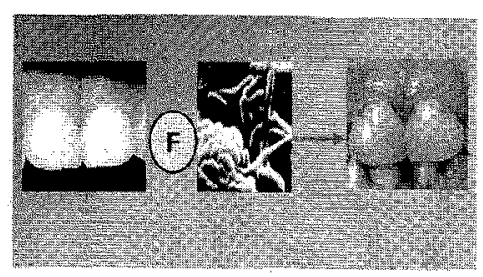

Eig. 8: El fluor actua inhibiendo la formación de placa bacteriana.

La incorporación de Flúor en la superficie del esmalte determinará un predominio de cargas negativas en la superficie del csmaltc estas al unirse a la carga negativa de las bacterias se producirá una repulsión traduciéndose con disminución en la formación de placa bacteriana necesitando para este propósito una concentración promedio de $30 \mathrm{ppm}$.

$5^{\circ}$ Antibacteriano.-

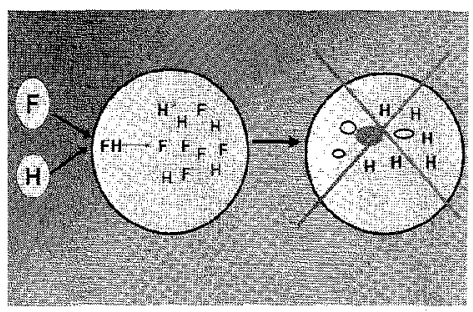

Fig.9: El flúor produce desorganización muerte bacteriana 
Normalmente existe una concentración elevada de hidrógeno en la saliva al entrar en contacto con una gran concentración de Flúor forma ácido fluorhídrico y de esta forma es como hace su ingreso al interior de la bacteria ya en su interior se vuelven a separar y es la concentración del hidrogenión que vuelve al medio interno un medio ácido provocando desorganización y muerte bacteriana para el logro de este mecanismo se requiere una concentración de 4000 a $6000 \mathrm{ppm}$ de ión fluor (fig. 9).

\section{Efectos sistémico y tópico del flúor}

Efecto sistémico

a) Pre-eruptivo

Tras su absorción intestinal y su paso a la sangre, el F se incorpora a la estructura mineralizada de los dientes en desarrollo y probablemente incrementa levemente la resistencia a la desmineralización frente a la acción de ácidos orgánicos 11 , ya que solamente un $8-10 \%$ de los cristales del esnualte están compuestos por FAP incluso en niños residentes en zonas con agua fluorada ${ }^{12}$.

Al principio de la investigación sobre el $F$, éste se creía que era el efecto más importante. Por ello, se recomendaba dar F a la embarazada así como antes de los 6 meses de vida (antes de la erupción del primer diente) y se aconsejaba retirar los suplementos tras la erupción de la segunda dentición, pues no tendría sentido su administración tras el desarrollo dental.

\section{b) Post-eruptivo}

Tras la erupción dental, tampoco el F sistémico estaría implicado en la formación de la estructura orgánica dental.

\section{Efecto tópico (post-eruptivo)}

Este es el que se cree más adecuado para prevenir la $\mathrm{CD}$. La saliva es el principal transportador del $\mathrm{F}$ tópico. La concentración de $\mathrm{F}$ en el duetus salivar tras la secreción de las glấndulas salivares es bajo $(0,016 \mathrm{ppm}$ en zonas con agua fluorada y $0,0006 \mathrm{ppm}$ en áreas con agua no fluorada) ${ }^{13}$. Esta concentración probablemente tenga una débil actividad cariostática. Sin embargo, la pasta dentífrica o los geles y barnices logran una concentración en la boca 100 a 1.000 veces superior.

Es importante reconocer que puede haber un efecto sistémico preeruptivo, pero de valor relativo, al momento de compararlo con el efecto posteruptivo, mucho más importante en la inhibición de la caries ${ }^{\mathrm{I}}$.

Para los infantes, la fluoración del agua, $y$ los barnices fluorados parecen ser los regímenes más adecuados.

Walter et al (1997) indican que en presencia de dientes debe iniciarse la fluorterapia casera diaria con fluoruro de sodio al $0,02 \%$ además de la aplicación de barniz con flúor ${ }^{13}$.

\section{Barnices de Flúor}

Los barnices a diferencia de las otras presentaciones de flúor, se caracterizan por su vehículo, un polimero clasificado como un sistema de matriz difusional de liberación sostenida, esto significa que la liberación disminuye exponencialmente con el tiempo no habiendose encontrado hasta el momento un sistema de liberación controlada, lo cual seria lo optimo

Desde su introducción en la década del 60 , los barnices fluorados se han convertido en la forma más comúnmente usada de aplicar flúor tópico en Eurom pa y su uso parece estar aumentando en el mundo.

Sin embargo, ninguna de sus presentaciones ha sido aceptado por el American Dental Association Council on Dental Therapeutics.

\section{Tipos de barniz de flúor}

En nuestro país se comercializan dos productos de barniz de flúor.

El primero, introducido por HF Schmidt fue el FNa en una base natural de colofonio comercializado con el nombre de Duraphat (Colgate Oral Pharmaceuticals), que contiene $5 \%$ (peso) de FNa o $2.26 \%$ (peso) de ion fluor (fig. 10). Cuando endurece en presencia de saliva, se convierte en una capa marrón- amarilla. ${ }^{3}$

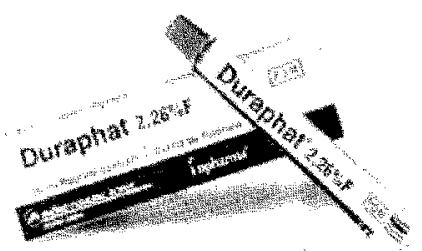

Fig. 10: Duraphat, tubo de 10ml

El otro barniz es el llamado Fluor Protector (Vivadent, Schaan, Liechtenstein) creado por Arends y Schuthof en 1975 (fig. 11).

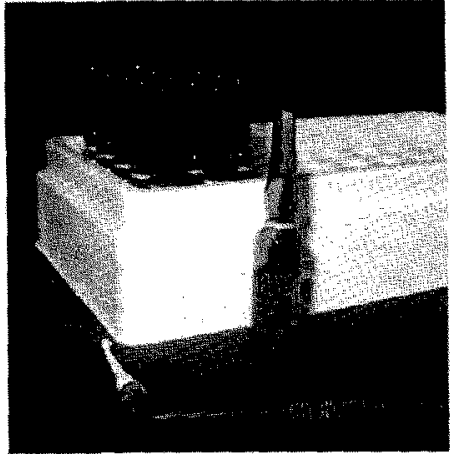

Fig. 11: Fluor Protector, ampollas $1 \mathrm{ml}$ $-0.4 \mathrm{ml}$

Es una laca basada en poliuretano que contiene $0.1 \%$ (peso) de ion fluoruro, como $1 \%$ (peso) de difluorsilano, ${ }^{3}$

A diferencia del anterior, este barniz es agrio pero de un color transparente después de su enclurecimiento al contacto con el aire, lo que constituye una gran ventaja estética con respecto al Duraphat. ${ }^{7,14}$

Un dato importante de señalar es que la FDA aprueba estas 2 marcas pero solo como barniz cavitario y para la sensibilidad dentinaria mas no como agente quinioterapeútico contra la caries dental. La FDA requiere más estudios clínicos para su aprobación final. ${ }^{7}$

\section{Ensayos clínicos}

\section{Efecto prezentivo}

Su efecto preventivo en dentición permanente, ha sido confirmado en numerosos ensayos clínicos. Un estudio de meta análisis de ocho estudios sobre barnices de fluoruro de sodio ( $\mathrm{F}$ $2.26 \%$ ) reportó un $38 \%$ de reducción de caries dental llegando a $47,06 \%$ luego de un año de aplicación (Helfenstein y Steiner, 1994) ${ }^{13}$

Para el caso de la dentición primaria, varios estudios han reportado porcentajes de prevención de $30-44 \%$. (Murray et al, 1997, Holm,1979, Weinstein el al, 1994) ${ }^{13}$

Otros estudios han encontrado que el barniz de flúor puede retrasar la progresión de caries incipiente de esmalte en dentición decidua.

Sin embargo los ensayos clinicos que respaldan su efecto resultan insuficientes para confirmar su efecto preventivo en dentición primaria ${ }^{24}$

Por otro lado, se ha encontrado una reducción en la desmineralización del esmalte debajo de bandas ortodónticas y brackets (Oogard, 1984, Kindelán, 1996) 7.24 
Flúor barniz vs. otras formas de aplicación del flúor

En algunos estudios comparativos, los barnices han demostrado alguna superioridad.

\begin{tabular}{c|c|c}
\hline Agente & (ppm F) & $\begin{array}{c}\% \text { Reducción } \\
\text { caries }\end{array}$ \\
\hline $\mathrm{NaF} 2 \%$ & 9,200 & 29 \\
\hline $\mathrm{APF}(1.2 \%)$ & 12,300 & 22 \\
\hline $8 \% \mathrm{SnF} 2$ & 19,500 & 32 \\
\hline $\begin{array}{c}\text { Barniz } \\
(5 \% \mathrm{NaF})\end{array}$ & 22,600 & 38 \\
\hline
\end{tabular}

Tabla 1. Efectividad de los agentes de flúor ${ }^{15}$

Koch(1979) demostró que los niños que recibieron tratamiento con Duraphat cada 6 meses tuvieron significativamente menos lesiones cariosas que el grupo que recibió enjuagatorios de $0,2 \%$ FNa semanalmente. Los mismos resultados se obtuvieron de comparar el barniz de fluor protector con enjuagatorios diarios de $0,2 \%$ de $\mathrm{FNa}$ (Axelsson 1987). ${ }^{15}$

Tewari et $\mathrm{a}^{16}$ compararon Duraphat con una solución de $\mathrm{NaF}$ al $2 \%$, el gel de fluorfosfato acidulado al $1,23 \%$ y con un grupo control. Reportaron que después de 2.5 años de estudio el barniz tuvo un porcentaje mayor de reducción de caries ( $74 \%$ ) respecto al $\mathrm{NaF} 2 \%(28 \%)$ y al FFA (37\%).

En otro estudio (Rodríguez y col , $1988)^{17}$ se concluye que los barnices, lacas y geles evaluados incrementan la resistencia del esmalte a la disolución ácida, siendo los barnices y lacas los más efectivos, concordando con lo postulado de que estos productos permiten una mayor impregnación de los iones de flúor en la estructura del esmalte.

Asimismo, Guitelman, I y col (1999) ${ }^{13}$ observaron que tanto el barniz de flúor $5 \%$ como la laca $\mathrm{FNa} 6 \%$ produjeron remineralización de manchas blancas cavitadas y no cavitadas pero la laca lo hizo en menor tiempo.

Por otro lado diversos estudios sugieren que existe un efecto preventivo similar entre las aplicaciones de flúor gel y flúor barniz

Al compararlo con el flúor fosfato acidulado Seppa et al (1995) ${ }^{18}$ no encontró diferencias significativas respecto de nuevas lesiones aparecidas luego de 3 años de aplicación del producto.
En un estudio de Cardozo y col ${ }^{19}$ se reporta que el flúor fosfato acidulado muestra mayor efectividad que el fluoruro de sodio y el barniz fluorado en cuanto a incrementar la resistencia del esmalte dental humano al ataque ácido

Con respecto a la prevención de caries oclusales, los barnices han sido comparados con los sellantes de fosas y fisuras encontrándose un mayor efecto preventivo con los sellante ( Holm, 1984, Bravo 1997) 7,14

\section{Concentraciones y frecuencia de apli-} cación

Se han reportado varios estudios acerca de la concentración y frecuencia de aplicación ideales.

En un estudio en ratas Seppa et a ${ }^{18}$ comprobó que el barniz de flúor al $2.26 \%$ reducía la progresión de caries de fosas y fisuras más que otras concentraciones.

Respecto a la frecuencia de aplicación existen diversas tendencias:

La Asociación Europea de Dentistas Pediátricos ${ }^{20}$ recomienda el siguiente esquema:

- Lesiones cariosas iniciales activas.. barnices en combinación con higiene adecuada.

- Dientes con focos de actividad cariosa débil o mediana. 1 a 2 aplicaciones al año.

- Niños con riesgo y actividad cariosa importante... 4 a 6 aplicaciones al año.

A pesar de csta recomendación, la Guía de la Scottish Intercollegiate Guidelines Network 21 recomienda su empleo cada 4 a 6 meses como máximo basándose en trabajos en los que se indica que la utilización más frecuente no aumenta la efectividad ${ }^{24}$.

Por otro lado Peterson et al (1991) ${ }^{14}$ usó Duraphat en un programa intenso con tres aplicaciones consecutivas dentro en un periodo de 10 días, una vez por año durante 3 años. Este modo de aplicación era significativamente mejor que dos aplicaciones por año.

En América latina, la Asociación Argentina de Odontología para Niños ${ }^{3}$ recomienda un protocolo de aplicación basado en el riego de caries individual:

Alto riego de caries

1. Tres aplicaciones de barniz de flúor en la primera semana, combinado con barniz de clorhexidina.
2. Una aplicación cada 2 meses hasta 1 año.

3. Reevaluación del riego de caries.

Mediano riesgo de caries

1. Aplicación de barniz de flúor cada 4 meses.

Bajo riesgo de caries

1. Aplicación de barniz de flúor cada 6 meses.

Considerando el riesgo de caries . Modeer et al., (1984) $7^{7}$ comprobó que las aplicaciones frecuentes (cada 3 meses) eran eficaces en niños con alto riesgo de caries.

En los cstudios de Seppa y Tolonen ${ }^{19}$ en niños con baja actividad de caries se concluye que no existen diferencias significativas al comparar la aplicación de Duraphat 3 o 4 veces al año respecto a la aplicación semianual

El protocolo recomendado basado en el riesgo y actividad de caries es:

- Los pacientes con actividad de caries reciben una fase de quimioterapia basada en la aplicación de barnices de clorhexidina y de flúor $(2600 \mathrm{ppm})$ con el objetivo principal de disminuir la cantidad de microorganismos en la cavidad bucal (clorhexidina), además de lograx remineralización, mineralización e inhibición de la formación de placa bacteriana (flúor).

La terapia es complementada con topicaciones diarias de flúor, con una solución de $\mathrm{FNa}$ al 0.05 $\%$ (226 ppm). La topicación debe realizarse por las noches después de la higiene oral y antes de acostarse; con la ayuda de un hisopo se aplica la solución dependiendo del número de piezas en boca, si presenta 4 piezas se requiere 4 gotas, si presenta más de cuatro piezas se requiere 8 gotas.

Los pacientes sin actividad pero con Riesgo alto de caries reciben el mismo protocolo de tratamiento que el grupo anteriormente mencionado.

Los pacientes sin actividad y con riesgo bajo de caries reciben $\mathrm{FNa}$ (gel) a altas concentraciones en la primera cita $(2 \%)$, para continuar con aplicaciones semanales (2 aplicaciones) de $\mathrm{FNa}$ al $0.02 \%$.

Todos los pacientes continúan con la fase de mantenimiento donde se les realiza la topicación con FNa al $2 \%$ (gel) con hisopo. Estas citas variarán en su 
frecuencia dependiendo de la actividad y riesgo de caries de cada paciente.

\section{Seguridad y toxicidad}

Las investigaciones indican que el riesgo de producir reacciones tóxicas con los barnices, es mínima. Asimismo el riesgo de producir fluorosis es mínimo ya que las exposiciones no son frecuentes, lo que si ocurre con otros suplementos de flúor. ${ }^{23}$

Del análisis de Eakstrand et al (1980) se concluyó que después de la aplicación del barniz , la más alta concentración de fluor en plasma, se alcanzó a las 2 horas, siendo este de $60-120 \mathrm{ng} / \mathrm{ml}$. Es conocido que niveles de fluor menores de $550 \mathrm{ng} / \mathrm{ml}$ en niños no producen toxicidad renal (Kharasch, 1996) ${ }^{24}$

Ningún efecto colateral frecuente se ha informado con respecto al tratamiento con los productos Duraphat y Fluor Protector. Sin embargo, no deben aplicarse los barnices fluorados en los tejidos gingivales sangrantes, debido al riesgo de alergia de contacto a la base de resina colofonia del Duraphat y al poliuretano del Fluor Protector.

\section{Referencias}

1. Minana V. Flúor y prevención de la caries en la infancia. Rev. Pediatría de Atención Primaria. Jul/Sept 2002; 4 (15)

2. Balda $\mathrm{R}$. Tratamiento de la enfermedad de caries dirigidoal agente causal. Uso de fluoruros. Acta odontol. venez. dic 1999; 37(3)

3. Castillo L. Importancia clínica de los barnices fluorados. Bol Asoc Arg Odont Niñ vol $30 n^{\circ} 1$ marzo/junio 2001

4. Mauro S, García R. Eficiencia de tres fluoruros concentrados para la estabilización de caries deesmalte. Bol Asoc
Arg Odont Niñ vol $33 n^{\circ} 2$ jun/sept 2004

5. Arends J, Ruben JL, Christoffersen J. Remineralization of human dentine in vitro. Caries Res. 1990;24(6):432-5

6. Jan Ekstrand. Nuevos conceptos del uso de fluoruros en Odontología. Bol Asoc Arg Odont Niñ vol $27 n^{\circ} 4$ dic /mar 1998/1999

7. Beltran-Agular E, Goldstein ]. Fluoride Varnishes A Review of their clinical use, Cariostatic Mechanism, Eficacy and Safety JADA, Vol. 131, May 2000

8. Brudevold F. et al. An enamel biopsy method for determination of fluoride in human teeth. Brudevold $\mathrm{F}$ et al Arch Oral Biol 1968;13: 877-885

9. Melberg Ir et al. The acquisition and loss of fluoride by topical fluoridated human tooth enamel. Arch Oral Biol 1966,11: 1213-1220

10. Van Loveren $C$. The antimicrobial action of fluoride and its role in caries inhibition. J Dent Res 1990; 69 (special isssue): 676-81.

11. American Dietetic Association.The impact of fluoride on health. J Am Diet Assoc. 2000; 100: 1208-1213.

12. Almerich JM. Odontologia preventiva y comunitaria. Ed. Masson. Barcelona. $2^{\text {a }}$ ed. 1999: 89-108.

13. Marinho V, Higgins J. Systematic Review of Controlled Trials on the Effectiveness of Fluoride Gels for the Prevention of Dental Caries in Children. J Dent Edu Volume 67, Number 4,2003

14. Kevin J. Donly D. Fluoride vamishes. Journal of the California Dental Assom ciation, March 2003

15. Newbrun E. Topical Fluorides in Caries Prevention and Management: $A$ North American Perspectiva. Journal of Dental Education. Volume 65, No. 10, October 2001.
16. Tewari $A$, Chawla HS, Utreja. Comparative evaluation of the role of $\mathrm{NaF}, \mathrm{APF} \&$ Duraphat topical fluoride applications in the prevention of dental caries-a 2 $1 / 2$ years study. AJ Indian Soc Pedod Prev Dent. 1991 Mar;8(1):28-35.

17. Rodriguez $\mathrm{M}$ y col. Estudio comparativo del incremento de la resistencia del esmalte a la disolución ácida mediante diversos tratamientos con fluoruros. Rev. Cubana Estomatol 25 (3): 22-27, septiembre- diciembre 1988

18. Seppa L. Fluoride varnishes in caries prevention. Med Princ Pract. 2004 Nov-Dec;13(6):307-11

19. De La Cruz C, Cardozo D, Camacho Guerrero E. Resistencia al ataque ácido en esmalte dental humano antes y despues de la aplicación topica de tres agentes fluorados. Revista ADM 2001 vol LVIII, $\mathrm{n}^{\circ} 1$ pp $31-35$

20. Marks L, Martens L. Utilisation du fluor chez les enfants: recommendations de 1'European Academy for Paediatric Dentistry. Rev Belg Med Dent 1998; 53: 318-324

21. Scottish Intercollegiate Guidelines Network Preventing Dental Caries in Children at High Caries Risk Targeted prevention of dental caries in the permanent teeth of 6-16 year olds presenting for dental care. $2000 ; 47$ : 1-33.

22. Guillén C, Loayza R, Torres G, Garibay $P$, Anticona $C$. Odontología para el bebé: El modelo de atención en Salud pública. Odontol San Marq 2004; 8(2)

23. Gómez G, Delgado M. Fluor y fluorosis dental. Pautas para el consumo de dentífricos y aguas de bebida en Canarias. $1^{a}$ edición: Santa Cruz de Tenerife, mayo 2002.

24. Fomon S, Ekstrand ], Ziegler E. Fluoride intake and prevalence of dental fluorosis: trends in fluoride intake with special attention to infants. J Public Health Dent. 2000; 60(3):131-9. 